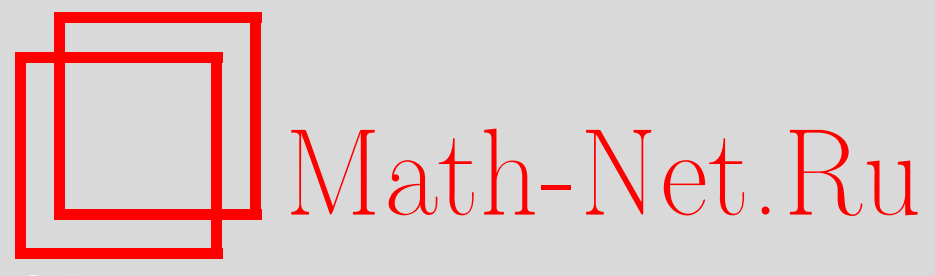

А. П. Янковский, Исследование установившейся ползучести металлокомпозитных балок слоистоволокнистой структуры с учетом ослабленного сопротивления поперечным сдвигам, Вестн. Сам. гос. техн. ун-та. Сер. Физ.-мат. науки, 2016, номep 1, 85-108

DOI: https://doi.org/10.14498/vsgtu1459

Использование Общероссийского математического портала MathNet.Ru подразумевает, что вы прочитали и согласны с пользовательским соглашением

http://www . mathnet.ru/rus/agreement

Параметры загрузки:

IP : 35.174 .16 .151

26 апреля 2023 г., 03:03:01

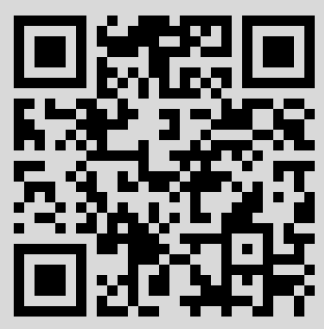


Вестн. Сам. гос. техн. ун-та. Сер. Физ.-мат. науки. 2016. Т. 20, № 1. С. 85-108

ISSN: 2310-7081 (online), 1991-8615 (print)

doi: http://dx.doi.org/10.14498/vsgtu1459

Механика деформируемого

твёрдого тела

удК 539.376

\title{
ИССЛЕДОВАНИЕ УСТАНОВИВШЕЙСЯ ПОЛЗУЧЕСТИ МЕТАЛЛОКОМПОЗИТНЫХ БАЛОК СЛОИСТО-ВОЛОКНИСТОЙ СТРУКТУРЫ С УЧЕТОМ ОСЛАБЛЕННОГО СОПРОТИВЛЕНИЯ ПОПЕРЕЧНЫМ СДВИГАМ
}

\section{А. П. Янковский}

Институт теоретической и прикладной механики им. С. А. Христиановича СО РАН, Россия, 630090, Новосибирск, ул. Институтская, 4/1.

\begin{abstract}
Аннотация
Рассмотрена установившаяся ползучесть гибридных изгибаемых металлокомпозитных слоистых балок нерегулярной структуры. Балки состоят из стенок и прикреплённых к ним сверху и снизу несущих слоёв (полок). Полки усилены проволоками в продольном направлении, а стенки армированы либо продольно, либо перекрёстно в своей плоскости. В рамках гипотез теории Тимошенко сформулирована соответствующая краевая задача расчёта таких балок, что позволило учесть ослабленное сопротивление их стенок поперечным сдвигам. Для линеаризации поставленной задачи использован метод простой итерации, основанный на идее метода секущего модуля. Исследовано механическое поведение в условиях установившейся ползучести армированных и неармированных двухопорных и консольных балок под действием равномерно распределённой поперечной нагрузки. Поперечные сечения балок представляют собой двутавры. Показано, что для однородных двутавровых балок классическая теория Бернулли не гарантирует получения расчётных результатов по податливости в пределах $20 \%$-й точности, считающейся приемлемой, особенно если ширина полок сопоставима с высотой поперечных сечений балок. В случаях металлокомпозитных балок классическая теория становится неприемлемой, так как занижает податливость таких конструкций в условиях установившейся ползучести на несколько порядков. Продемонстрировано, что для адекватного расчёта металлокомпозитных балок слоисто-волокнистой структуры необходимо учитывать в их стенках активно развивающиеся скорости деформаций поперечных сдвигов. Учёт этих скоростей деформаций в рамках теории Тимошенко позволил обнаружить новые «механизмы» деформирования слоистых балок, которые не позволяет выявить классическая теория. Показано, что при увеличении плотности армирования полок или стенки может произойти смена «механизмов» деформирования.
\end{abstract}

(C) 2016 Самарский государственный технический университет.

\section{Образец для цитирования}

Я н к о в с к и й А. П. Исследование установившейся ползучести металлокомпозитных балок слоисто-волокнистой структуры с учетом ослабленного сопротивления поперечным сдвигам // Вестн. Сам. гос. техн. ун-та. Сер. Физ.-мат. науки, 2016. Т. 20, № 1. С. 85-108. doi: $10.14498 /$ vsgtu1459.

Сведения об авторе

Андрей Петрович Янковский (д.ф.-м.н.; lab4nemir@rambler.ru), ведущий научный сотрудник, лаб. физики быстропротекающих процессов. 
Ключевые слова: металлокомпозиты, армирование, слоистые балки, установившаяся ползучесть, теория Тимошенко, теория Бернулли, неединственность решения.

Введение. Несущие каркасы современных инженерных сооружений представляют собой совокупность силовых элементов стержневого типа колонн, балок, ферм, рам и т. п. Цель расчётов таких каркасов по условиям прочности, податливости и устойчивости состоит в обеспечении достаточной, но не чрезмерно избыточной безопасности, т. е. в достижении сбалансированного сочетания надёжности с экономичностью. В связи с этим активное развитие получили методы оптимального проектирования силовых элементов сооружений $[1,2$ и др.]. В настоящее время особые надежды возлагаются на создание гибридных композитных конструкций, несущие элементы которых создаются на основе сочетания материалов с разными механическими характеристиками [3].

Известно, что при длительном нагружении металлоконструкций (в том числе состоящих из металлокомпозитных несущих элементов) большую часть времени они функционируют в условиях установившейся ползучести [4-6 и др.], поэтому актуальной является проблема адекватного расчёта металлокомпозитных несущих элементов конструкций, работающих в этих условиях.

Исследования различных вопросов одноосного и изгибного деформирования в условиях ползучести стержневых и изгибаемых элементов, изготовленных из традиционных конструкционных металлических материалов, приведены, например, в [4-6 и др.]. Теория же расчёта изгибаемых металлокомпозитных балок, рам и т. п. (в частности слоистой, волокнистой и слоистоволокнистой структуры), работающих в условиях ползучести, находится пока в стадии становления. Так, в [2, 7 и др.] изучались вопросы изгибного деформирования слоистых металлокомпозитных балок и рам, работающих в условиях ползучести. Основные разрешающие уравнения в этих работах, как и в $[4,5]$, получены в рамках гипотез классической теории Бернулли. Однако известно, что в рационально спроектированной балке (необязательно металлокомпозитной) несущие слои (полки) целесообразно разнести и соединить тонкой стенкой [2, 8 и др.]. Пренебрежение же деформациями поперечного сдвига в тонкой стенке профилированной балки (что имеет место в рамках гипотезы плоских сечений классической теории) может привести к значительному занижению оценки её податливости, особенно в случае нелинейного поведения материала конструкции (например, при работе в условиях установившейся ползучести [4-6]), а значит, в конечном итоге - и к неверным решениям задач оптимального и рационального проектирования.

Для продольно армированных металлокомпозитных балок-стенок квазиоднородной структуры необходимость учёта ослабленного сопротивления поперечным сдвигам в условиях установившейся ползучести продемонстрирована в [9]. В связи с этим настоящее исследование посвящено построению неклассической теории изгибного деформирования в условиях установившейся ползучести гибридных металлокомпозитных балок слоисто-волокнистой структуры и сравнению результатов расчётов, полученных на её основе, с аналогичными результатами классической теории. 
1. Постановка задачи. В декартовой прямоугольной системе координат $x_{i}$ рассмотрим прямолинейную балку длиной $L$; ось $x_{1}$ направим вдоль оси балки, а $x_{2}$ - по её высоте (рис. 1). Композитная балка представляет собой слоистый пакет нерегулярной структуры; слои выполнены из однородных изотропных металлических или квазиоднородных металлокомпозитных армированных материалов. Этот многослойный пакет обладает свойством симметрии относительно плоскости $x_{1} x_{2}$ (рис. 2). Слои контактируют между собой без проскальзывания.

Как уже отмечалось, в рационально спроектированной балке несущие слои должны быть разнесены и соединены между собой стенкой, которую условимся называть слоем с номером $m=0$. Пронумеруем несущие слои (полки), расположенные выше стенки, снизу вверх от 1 до $M^{(+)}\left(1 \leqslant m \leqslant M^{(+)}\right)$, а несущие слои, лежащие ниже стенки, пронумеруем сверху вниз от -1 до $-M^{(-)}\left(-M^{(-)} \leqslant m \leqslant-1, M^{(-)}>0\right)$. Так, на рис. 2 , а изображен случай $M^{(+)}=M^{(-)}=2$, т. е. балка состоит из пяти слоёв (причём слои с номерами $m=2, m=-1$ и стенка армированы), а на рис. $2, b$ и 2, с изображены случаи $M^{( \pm)}=1$, т. е. соответствующие балки являются трёхслойными (причём на рис. $2, d$ несущие слои $(m= \pm 1)$ армированы). Значения $M^{( \pm)}=1$ и $M^{( \pm)}=2$ позволяют описать большинство случаев, наблюдаемых при проектировании стержневых систем на практике [2].

Свяжем с балкой систему координат $x_{i}$ так, чтобы плоскость $x_{1} x_{3}\left(x_{2}=0\right)$ проходила через срединный слой стенки $(m=0)$.

В настоящем исследовании для простоты ограничимся случаем (хотя это и не принципиально), когда поперечное сечение каждого слоя - прямоугольник с размерами $b_{m} \times h_{m},-M^{(-)} \leqslant m \leqslant M^{(+)}$(см. рис. 2, a), где $b_{m}, h_{m}-$ ширина и толщина $m$-го слоя; в случае $m=0$ под $h_{0}=2 h$ понимается высота

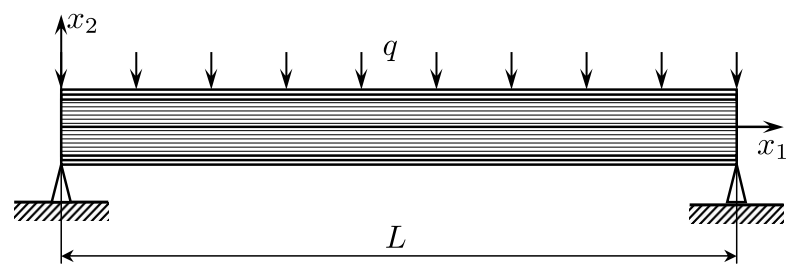

a

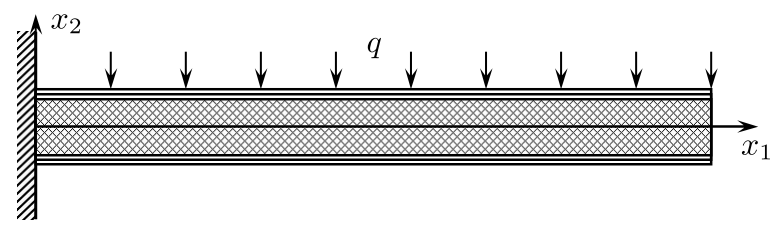

$b$

Рис. 1. Слоистые балки нерегулярной структуры: а) шарнирно опертая (с продольным армированием стенки); b) консольная (с перекрестным армированием стенки)

[Figure 1. Laminated composite beams with irregular structure, including (a) a pin-ended beam with a longitudinal reinforcement wall, $(b)$ a clamped-free beam with a cross reinforcement wall] 


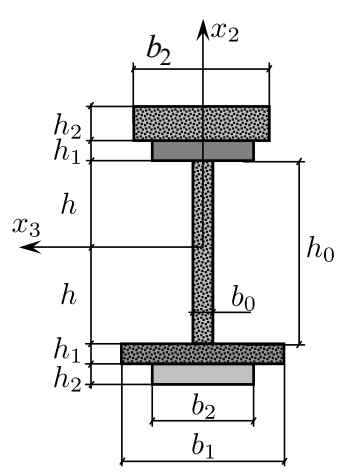

a

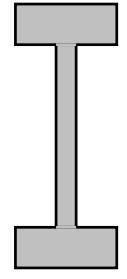

$b$

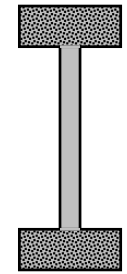

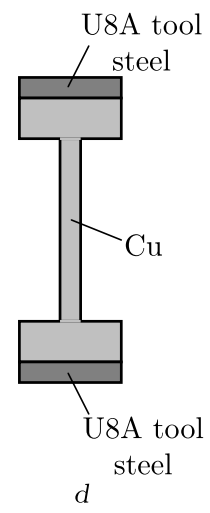

$d$

U8A Tool Steel Composition (percent by mass): 0.76-0.83 C, $0.17-0.33 \mathrm{Si}$, $0.17-0.28 \mathrm{Mn}, \leqslant 0.2 \mathrm{Ni}, \leqslant 0.018 \mathrm{~S}, \leqslant 0.025 \mathrm{P}, \leqslant 0.2 \mathrm{Cr}, \leqslant 0.2 \mathrm{Cu}, \sim 98 \mathrm{Fe}$

Рис. 2. Поперечные сечения слоистой балки: а) произвольной пятислойной структуры (с армированными внешними слоями и стенкой); b) двутавровой однородной; $c$ ) двутавровой с армированными полками; $d$ ) двутавровой с усиливающими внешними изотропными накладками

[Figure 2. Beam cross sections, including (a) an arbitrary five-layer structure with a reinforced outer layers and outer layer of the wall, (b) a homogeneous I-beam, $(c)$ a reinforced I-beam,

$(d)$ an I-beam with reinforcing external isotropic plates]

стенки, а под $b_{0}$ - её толщина. (Описание более сложной геометрии поперечного сечения слоистой балки дано в [2].)

Рассматривается случай, когда толщина несущих слоёв (полок) существенно меньше высоты стенки, а ширина полок много больше толщины стенки:

$$
h_{m} \ll h_{0}, \quad b_{0} \ll b_{m}, \quad-M^{(-)} \leqslant m \leqslant M^{(+)}, \quad m \neq 0 ;
$$

кроме того, ширина полок не слишком велика, а сопоставима с высотой стенки:

$$
b_{m} \approx h_{0}=2 h, \quad-M^{(-)} \leqslant m \leqslant M^{(+)}, \quad m \neq 0,
$$

т. е. балка не является тонкостенным стержнем (последнее имеет место, например, при $b_{m} \gg h_{0},-M^{(-)} \leqslant m \leqslant M^{(+)}, m \neq 0$ [10]). Соотношения (2) выполняются, в частности, для прокатных двутавровых профилей [8].

Делаются следующие предположения: начальными деформациями можно пренебречь по сравнению с накопленными деформациями ползучести [4,5]; прогибы малы; температура конструкции однородна; материалы компонентов композиции одинаково сопротивляются растяжению и сжатию; решение задачи не зависит от переменной $x_{3}$, т. е. изгиб в плоскости $x_{1} x_{3}$ и кручение балки не рассматриваются. (В случае широких полок, т. е. при $b_{m} \gg h_{0}$ $(m \neq 0)$, необходимо учитывать изменяемость деформированного стояния полок по координате $x_{3}[10]$, поэтому случай тонкостенных стержней с широкими полками в настоящей работе не изучается.)

Для описания ослабленного сопротивления стенки $(m=0)$ рассматриваемой металлокомпозитной балки поперечному сдвигу в плоскости $x_{1} x_{2}$, согласно (1) и (2), используем гипотезы теории Тимошенко $[11,12]$, т. е. для скоростей установившейся ползучести точек балки примем следующие аппроксимации:

$$
v_{1}\left(x_{1}, x_{2}\right)=v_{1}^{0}\left(x_{1}\right)-x_{2} \theta\left(x_{1}\right), \quad v_{2}\left(x_{1}, x_{2}\right)=v_{2}^{0}\left(x_{1}\right), \quad 0 \leqslant x_{1} \leqslant L,
$$


где $v_{2}^{0}$ - скорость прогиба; $v_{1}^{0}$ - скорость точек срединного слоя стенки $\left(x_{2}=0\right)$ в продольном направлении $x_{1} ; \theta$ - скорость угла поворота поперечного сечения балки вокруг оси $x_{3}$.

Используя (3) и дифференциальные соотношения Коши [4,5], получим выражения для скоростей деформаций установившейся ползучести:

$$
\begin{gathered}
\xi_{11}\left(x_{1}, x_{2}\right)=\partial_{1} v_{1}=\partial_{1} v_{1}^{0}\left(x_{1}\right)-x_{2} \partial_{1} \theta\left(x_{1}\right), \quad 0 \leqslant x_{1} \leqslant L \\
2 \xi_{12}\left(x_{1}, x_{2}\right)=\partial_{1} v_{2}+\partial_{2} v_{1}=\partial_{1} v_{2}^{0}\left(x_{1}\right)-\theta\left(x_{1}\right)=2 \xi_{12}^{0}\left(x_{1}\right), \quad 0 \leqslant x_{1} \leqslant L,
\end{gathered}
$$

где $\partial_{i}$ - оператор дифференцирования по переменной $x_{i}$. Из последнего равенства (5) выразим $\theta$ и исключим его из $(3),(4)$, тогда получим

$$
\begin{gathered}
v_{1}\left(x_{1}, x_{2}\right)=v_{1}^{0}\left(x_{1}\right)-x_{2} \partial_{1} v_{2}^{0}\left(x_{1}\right)+2 x_{2} \xi_{12}^{0}\left(x_{1}\right), \quad 0 \leqslant x_{1} \leqslant L \\
\xi_{11}\left(x_{1}, x_{2}\right)=\partial_{1} v_{1}^{0}\left(x_{1}\right)-x_{2} \partial_{1}^{2} v_{2}^{0}\left(x_{1}\right)+2 x_{2} \partial_{1} \xi_{12}^{0}\left(x_{1}\right), \quad 0 \leqslant x_{1} \leqslant L .
\end{gathered}
$$

Каждый $m$-й слой может быть квазиоднородно армирован $K^{(m)}$ семействами металлических волокон (проволок) с плотностями армирования $\omega_{k}^{(m)}$ $\left(1 \leqslant k \leqslant K^{(m)}\right)$. Относительное объёмное содержание материала связующего в пределах представительного элемента композиции слоя обозначим $\omega_{0}^{(m)}$, тогда имеет место условие нормировки

$$
\sum_{k=0}^{K^{(m)}} \omega_{k}^{(m)}=1, \quad-M^{(-)} \leqslant m \leqslant M^{(+)}
$$

Предполагается, что несущие слои (полки) армированы только в осевом (продольном) направлении $x_{1}$, поэтому на основании $(1),(2)$ в рамках теории Тимошенко с приемлемой для инженерных приложений точностью можно считать, что во всех компонентах композиции несущих слоев реализуется одноосное напряженное состояние. При этом для несущих слоёв рассматриваемой балки справедливы следующие определяющие уравнения установившейся ползучести $[4,5,9,13]$ :

$$
\begin{gathered}
\sigma_{11}^{(m)}=a_{11}^{(m)}\left(\xi_{11}\right) \xi_{11}, \quad H_{m-1} \leqslant x_{3}<H_{m} \\
0 \leqslant x_{1} \leqslant L, \quad-M^{(-)} \leqslant m \leqslant M^{(+)}, \quad m \neq 0
\end{gathered}
$$

где

$$
a_{11}^{(m)}\left(\xi_{11}\right)=\sum_{k=0}^{K^{(m)}} \omega_{k}^{(m)} g_{k}^{(m)}\left(\xi_{11}\right), \quad-M^{(-)} \leqslant m \leqslant M^{(+)}, \quad m \neq 0 .
$$

В стенке же $(m=0)$ рассматриваемой балки реализуется плоское напряжённое состояние (ПНС). Армирование стенки может быть перекрёстным в плоскости $x_{1} x_{2}$, а направление армирования волокном $k$-го семейства определяется углом $\varphi_{k}$, отсчитываемым от направления $x_{1}$ (рис. 3 ). Так как при ПНС $\sigma_{13}^{(0)}=\sigma_{23}^{(0)}=0$, для металлокомпозитной стенки справедливы следующие определяющие уравнения установившейся ползучести [13]:

$$
\sigma_{i i}^{(0)}=a_{i 1}^{(0)} \xi_{11}+a_{i 2}^{(0)} \xi_{22}+a_{i 3}^{(0)} \xi_{12}, \quad a_{12}^{(0)}=a_{21}^{(0)}, \quad i=1,2
$$




$$
\sigma_{12}^{(0)}=a_{31}^{(0)} \xi_{11}+a_{32}^{(0)} \xi_{22}+a_{33}^{(0)} \xi_{12}, \quad 2 a_{3 i}^{(0)}=a_{i 3}^{(0)}, \quad i=1,2
$$

В равенствах (9)-(12) приняты следующие обозначения: $\sigma_{i j}^{(m)}$-осреднённые напряжения в композиции $m$-го слоя; $a_{i j}^{(m)}$ - эффективные вязкости установившейся ползучести металлокомпозитного материала $m$-го слоя; $g_{k}^{(m)}-$ известный секущий модуль материала $k$-го компонента композиции $m$-го слоя $(m \neq 0)$, определённый из экспериментальной зависимости $\sigma_{11}=g_{k}^{(m)}\left(\xi_{11}\right) \xi_{11}$ при одноосном растяжении-сжатии в условиях установившейся ползучести; $H_{m}$ - ордината границы между $m$-м и $(m+1)$-м слоями. Коэффициенты $a_{i j}^{(0)}$ в (11)), (12) являются ненулевыми компонентами матрицы $A$, определяемой матричным соотношением (53) в [13], зависящими от свойств материалов фаз композиции стенки (от величин, аналогичных $g_{k}^{(0)}\left(\xi_{11}\right)$ ) и от параметров армирования $\omega_{k}^{(0)}, \varphi_{k}$ (см. (8) и рис. 3 ).

Исходя из неравенства $\left|\sigma_{11}^{(0)}\right| \gg\left|\sigma_{22}^{(0)}\right|$, являющегося традиционным допущением теории балок $[2,4,6,8,11]$, во втором равенстве (11) приближённо можно принять $\sigma_{22}^{(0)}=0$ и за счёт этого исключить из (12) и первого соотношения (11) скорость деформаций ползучести композиции $\xi_{22}$. Тогда для стенки окончательно получим следующие определяющие уравнения:

$$
\begin{aligned}
& \sigma_{11}^{(0)}=A_{11}^{(0)} \xi_{11}+A_{12}^{(0)} \xi_{12}, \quad \sigma_{12}^{(0)}=\frac{1}{2} A_{12}^{(0)} \xi_{11}+A_{22}^{(0)} \xi_{12}, \\
& \xi_{22}=-\left(a_{21}^{(0)} \xi_{11}+a_{23}^{(0)} \xi_{12}\right) / a_{22}^{(0)}, \quad\left|x_{2}\right| \leqslant h, \quad 0 \leqslant x_{1} \leqslant L,
\end{aligned}
$$

где

$$
\begin{gathered}
A_{11}^{(0)} \equiv a_{11}^{(0)}-a_{12}^{(0)} a_{12}^{(0)} / a_{22}^{(0)}, \quad A_{12}^{(0)} \equiv a_{13}^{(0)}-a_{12}^{(0)} a_{23}^{(0)} / a_{22}^{(0)}, \\
A_{22}^{(0)} \equiv a_{33}^{(0)}-a_{23}^{(0)} a_{23}^{(0)} /\left(2 a_{22}^{(0)}\right) .
\end{gathered}
$$

На основании соотношений (9), (13) с учётом (5), (7), (10), (14) можем вычислить все внутренние силовые факторы в балке:

$$
\begin{aligned}
& F_{11}\left(x_{1}\right)=A_{11} \partial_{1} v_{1}^{0}\left(x_{1}\right)-B_{11} \partial_{1}^{2} v_{2}^{0}\left(x_{1}\right)+2 C_{11} \partial_{1} \xi_{12}^{0}\left(x_{1}\right)+F_{11}^{0} \xi_{12}^{0}\left(x_{1}\right), \\
& M_{11}\left(x_{1}\right)=B_{11} \partial_{1} v_{1}^{0}\left(x_{1}\right)-D_{11} \partial_{1}^{2} v_{2}^{0}\left(x_{1}\right)+2 E_{11} \partial_{1} \xi_{12}^{0}\left(x_{1}\right)+M_{11}^{0} \xi_{12}^{0}\left(x_{1}\right), \\
& F_{12}\left(x_{1}\right)=A_{55} \xi_{12}^{0}\left(x_{1}\right)+F_{12}^{0}\left(x_{1}\right), \quad 0 \leqslant x_{1} \leqslant L,
\end{aligned}
$$

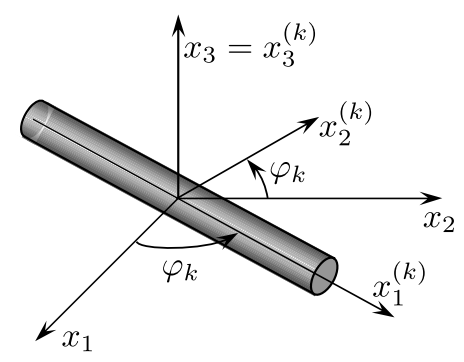

Рис. 3. Система координат, связанная с арматурой $k$-го семейства в стенке [Figure 3. Coordinate system related to reinforcing fibers] 
где

$$
\begin{aligned}
& F_{1 i}\left(x_{1}\right)=\iint_{S} \sigma_{1 i} d S=\sum_{m=-M^{(-)}}^{M^{(+)}} \iint_{S_{m}} \sigma_{1 i}^{(m)} d S \quad(i=1,2), \\
& M_{11}\left(x_{1}\right)=\iint_{S} \sigma_{11} x_{2} d S=\sum_{m=-M^{(-)}}^{M^{(+)}} \iint_{S_{m}} \sigma_{11}^{(m)} x_{2} d S \\
& A_{11}\left(x_{1}\right)=b_{0} \int_{-h}^{h} A_{11}^{(0)} d x_{2}+\sum_{m=-M^{(-)}}^{M^{(+)}}\left(1-\delta_{0 m}\right) b_{m} h_{m} a_{11}^{(m)}\left(\xi_{11}^{(m)}\right) \text {, } \\
& B_{11}\left(x_{1}\right)=C_{11}\left(x_{1}\right)=b_{0} \int_{-h}^{h} A_{11}^{(0)} x_{2} d x_{2}+ \\
& +\sum_{m=-M^{(-)}}^{M^{(+)}} \operatorname{sign}(m) b_{m} h_{m} x_{2}^{(m)} a_{11}^{(m)}\left(\xi_{11}^{(m)}\right) \\
& D_{11}\left(x_{1}\right)=E_{11}\left(x_{1}\right)=b_{0} \int_{-h}^{h=-M^{(-)}} A_{11}^{(0)} x_{2}^{2} d x_{2}+ \\
& +\sum_{m=-M^{(-)}}^{M^{(+)}}\left(1-\delta_{0 m}\right) b_{m} h_{m}\left(x_{2}^{(m)}\right)^{2} a_{11}^{(m)}\left(\xi_{11}^{(m)}\right) \\
& A_{55}\left(x_{1}\right)=b_{0} \int_{-h}^{h} A_{22}^{(0)} d x_{2}, \quad F_{12}^{0}\left(x_{1}\right)=\frac{b_{0}}{2} \int_{-h}^{h} A_{12}^{(0)} \xi_{11} d x_{2}, \\
& F_{11}^{0}\left(x_{1}\right)=b_{0} \int_{-h}^{h} A_{12}^{(0)} d x_{2}, \quad M_{11}^{0}\left(x_{1}\right)=b_{0} \int_{-h}^{h} A_{12}^{(0)} x_{2} d x_{2} \text {, } \\
& \xi_{11}^{(m)}=\xi_{11}\left(x_{1}, x_{2}^{(m)}\right), \quad-M^{(-)} \leqslant m \leqslant M^{(+)}, \quad m \neq 0 ;
\end{aligned}
$$

$\delta_{0 m}$ - символ Кронекера; $x_{2}^{(m)}$ - ордината центра тяжести поперечного сечения $m$-го слоя; $S$ - площадь поперечного сечения балки; $S_{m}$ - площадь поперечного сечения $m$-го слоя балки (в настоящем исследовании $S_{m}=b_{m} h_{m}$ ); $F_{11}, F_{12}$ - продольная и поперечная силы соответственно; $M_{11}$ - изгибающий момент.

В выражениях для коэффициентов $A_{11}, B_{11}, C_{11}, D_{11}, E_{11}$ (см. (16)) интегралы по поперечным сечениям несущих слоев $(m \neq 0)$ на основании $(1)$ вычислены приближённо по правилу средней точки, т. е. при их определении не учитывалась изменяемость функций $\sigma_{11}^{(m)} x_{2}^{l}$ по переменной $x_{2}$, а приближённо принималось $\sigma_{11}^{(m)}\left(x_{1}, x_{2}\right) x_{2}^{l}=\sigma_{11}^{(m)}\left(x_{1}, x_{2}^{(m)}\right)\left(x_{2}^{(m)}\right)^{l}\left(H_{m-1} \leqslant x_{2}<H_{m}\right.$, $m \neq 0, l=0,1,2)$. Кроме того, в правых частях соотношений (15) для коэффициентов $A_{11}, B_{11}, C_{11}, D_{11}, E_{11}, A_{55}$ сохранены те же обозначения, что и в [9] (см. там формулу (12)).

В силу ограниченности объёма статьи в настоящей работе исследуем изгибное поведение только статически определимых балок. При этом левые части в соотношениях (15) являются известными функциями переменной $x_{1}$. Так, в случае равномерно нагружённой двухопорной балки (рис. 1, а) силовые 
факторы имеют следующие выражения [8,9]:

$$
\begin{aligned}
& F_{11}\left(x_{1}\right) \equiv 0, \quad F_{12}\left(x_{1}\right)=q\left(x_{1}-L / 2\right), \\
& 2 M_{11}\left(x_{1}\right)=q x_{1}\left(x_{1}-L\right), \quad 0 \leqslant x_{1} \leqslant L
\end{aligned}
$$

в случае же равномерно нагруженной консольной балки (рис. $1, b)$ -

$$
\begin{aligned}
& F_{11}\left(x_{1}\right) \equiv 0, \quad F_{12}\left(x_{1}\right)=q\left(x_{1}-L\right), \\
& 2 M_{11}\left(x_{1}\right)=q\left(L-x_{1}\right)^{2}, \quad 0 \leqslant x_{1} \leqslant L .
\end{aligned}
$$

Согласно (5), (7), (9), (10), (13), (14), (16) и равенствам (51), (53)-(56) из [13], соотношения (15) являются нелинейными. Для линеаризации этих равенств используем метод простой итерации, аналогичный методу секущего модуля $[4,9,13]$, т. е. предположим, что на некоторой $n$-й итерации известны функции $v_{1}^{0}, v_{2}^{0}, \xi_{12}^{0}$, тогда на основании $(5),(7)$ известны $n$-ые приближения скорости деформаций ползучести $\xi_{11}^{n}, \xi_{12}^{n}$ во всех точках балки. Поэтому, используя (10) и соотношения (51), (53) из [13], можем вычислить $n$-ые приближения коэффициентов $a_{11}^{(m)}(m \neq 0), a_{i j}^{(0)}$ в равенствах $(9),(11),(12)$, а затем по формулам (14) можем определить $n$-ые приближения коэффициентов $n$

$A_{i j}^{(0)}$ в определяющих уравнениях (13). В рамках метода последовательных приближений соотношения (15) для статически определимых балок можно записать в виде

$$
\begin{aligned}
& \stackrel{n}{A_{11}} \partial_{1} \stackrel{n+1}{v_{1}^{0}}\left(x_{1}\right)-\stackrel{n}{B_{11}} \partial_{1}^{2} \stackrel{n+1}{v_{2}^{0}}\left(x_{1}\right)+ \\
& +2 \stackrel{n}{C_{11}} \partial_{1}{\stackrel{n+1}{\xi_{12}^{0}}}^{0}\left(x_{1}\right)+F_{11}^{n} \stackrel{n+1}{\xi_{12}^{0}}\left(x_{1}\right)=F_{11}\left(x_{1}\right), \\
& \stackrel{n}{B_{11}} \partial_{1} \stackrel{n+1}{v_{1}^{0}}\left(x_{1}\right)-\stackrel{n}{D_{11}} \partial_{1}^{2} \stackrel{n+1}{v_{2}^{0}}\left(x_{1}\right)+
\end{aligned}
$$

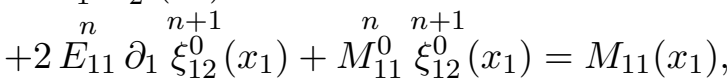

$$
\begin{aligned}
& \stackrel{n}{A_{55}} \stackrel{n+1}{\xi_{12}^{0}}\left(x_{1}\right)+\stackrel{n}{F}_{12}^{0}\left(x_{1}\right)=F_{12}\left(x_{1}\right), \quad 0 \leqslant x_{1} \leqslant L,
\end{aligned}
$$

$n+1 \quad n+1, n+1$
где $v_{1}^{0}, v_{2}^{0}, \xi_{12}^{0}$ - разыскиваемые на текущей $(n+1)$-й итерации приближения неизвестных функций $v_{1}^{0}, v_{2}^{0}, \xi_{12}^{0}$; известные коэффициенты $A_{11}^{n}, \stackrel{n}{B_{11}}=\stackrel{n}{C_{11}}$, $\stackrel{n}{D_{11}}=\stackrel{n}{E_{11}}, \stackrel{n}{A_{55}}, \stackrel{n}{F_{11}^{0}}, \stackrel{n}{M_{11}^{0}}$ и функция $F_{12}^{0}\left(x_{1}\right)$ вычисляются по формулам при следующих заменах: $A_{i j}^{(0)} \rightarrow A_{i j}^{(0)}, \xi_{11}^{(m)} \rightarrow \xi_{11}^{(m)}, \xi_{11} \rightarrow \stackrel{n}{\rightarrow} \xi_{11}(i, j=1,2)$.

Решение линейной системы $(19)$ на $(n+1)$-й итерации строится следующим образом. Из третьего равенства (19) с учётом (17) или (18) определяем

$$
\xi_{12}^{n+1}\left(x_{1}\right)=\frac{1}{A_{55}\left(x_{1}\right)}\left(F_{12}\left(x_{1}\right)-F_{12}^{0}\left(x_{1}\right)\right), \quad 0 \leqslant x_{1} \leqslant L,
$$


затем при известной функции $\stackrel{n+1}{\xi_{12}^{0}}\left(x_{1}\right)$ из двух первых равенств $(19)$ как из системы линейных алгебраических уравнений вычисляем производные $\partial_{1} v_{1}^{0}$,

$\partial_{1}^{2} v_{2}^{0+1}\left(0 \leqslant x_{1} \leqslant L\right)$. Интегрируя эти функции необходимое число раз с учётом соответствующих кинематических граничных условий, получим $(n+1)$-е приближения искомых функций $v_{1}^{0}, v_{2}^{0}$.

В случае двухопорной балки (рис. 1, а) кинематические граничные условия имеют вид

$$
\stackrel{n+1}{v_{1}^{0}}(0)=0, \quad \stackrel{n+1}{v_{2}^{0}}(0)=\stackrel{n+1}{v_{2}^{0}}(L)=0,
$$

а в случае консольной балки (рис. $1, b)$, согласно (6), имеем

$$
\stackrel{n+1}{v_{1}^{0}}\left(x_{1}\right)=0, \quad \stackrel{n+1}{v_{2}^{0}}\left(x_{1}\right)=0, \quad \partial_{1} v_{2}^{0}\left(x_{1}\right)=2 \stackrel{n+1}{\xi_{12}^{0}}\left(x_{1}\right), \quad x_{1}=0
$$

где значение $\xi_{12}^{n+1}(0)$ известно из $(20)$ при $x_{1}=0$.

2. Обсуждение результатов расчетов. В качестве конкретных примеров исследуем механическое поведение в условиях установившейся ползучести слоистых однородных и металлокомпозитных балок, изображенных на рис. 1 и имеющих длину $L=2$ м. Слои балок изготовлены из меди или стали марки У8А или представляют собой металлокомпозит, состоящий из меди, армированной стальной проволокой У8А.

Предполагается, что установившаяся ползучесть компонентов композиции описывается степенным законом $\xi=A_{k}^{(m)} \sigma_{k}^{\mu_{k}^{(m)}}$. Характеристики установившейся ползучести материалов компонентов композиции слоёв балки приведены ниже $[14,15]$.

$$
\text { Медь }(\mathrm{Cu}): \quad \mu=2.16 \quad A=5.63 \cdot 10^{-9}(\mathrm{MПа})^{-\mu} \cdot ч^{-1}
$$

Сталь марки У8А: $\quad \mu=24.89 \quad A=1.054 \cdot 10^{-84}(\mathrm{MПа})^{-\mu} \cdot \mathrm{ч}^{-1}$.

При этом секущие модули в несущих слоях $g_{k}^{(m)}\left(\xi_{11}\right)($ см. $(10))$ определяются так [4]:

$$
\begin{gathered}
g_{k}^{(m)}\left(\xi_{11}\right)=B_{k}^{(m)} \xi_{11}^{\eta_{k}^{(m)}-1}, \quad \eta_{k}^{(m)}=\frac{1}{\mu_{k}^{(m)}, \quad B_{k}^{(m)}=\left(A_{k}^{(m)}\right)^{-\eta_{k}^{(m)}},} \\
0 \leqslant k \leqslant K^{(m)}, \quad-M^{(-)} \leqslant m \leqslant M^{(+)}, \quad m \neq 0,
\end{gathered}
$$

где значения постоянных $\mu_{k}^{(m)}, A_{k}^{(m)}$ для материала $k$-й фазы композиции $m$-го слоя при температуре $200{ }^{\circ} \mathrm{C}$ приведены выше.

Так как в стенке $(m=0)$ рассматриваемой балки реализуется ПНС, выражения для секущего модуля материала $k$-го компонента композиции стенки отличаются от (23) и определяются более сложными соотношениями (48) из [13], которые не будем здесь приводить.

В качестве меры податливости балок в полученных решениях рассмотрим величину

$$
v_{2}^{*}=\max _{0 \leqslant x_{1} \leqslant L}\left|v_{2}^{0}\left(x_{1}\right)\right|
$$


Для сравнения же решений, найденных на основе классической теории и теории Тимошенко, используем отношение

$$
\delta v_{2}=\frac{v_{2}^{\mathrm{T}}-v_{2}^{\mathrm{B}}}{v_{2}^{\mathrm{T}}} \cdot 100 \%,
$$

где $v_{2}^{\mathrm{T}}-$ значение величины $v_{2}^{*}$, вычисленное по теории Тимошенко; $v_{2}^{\mathrm{B}}-$ значение $v_{2}^{*}$, определённое по теории Бернулли.

На рис. 4, 5 изображены эпюры скоростей прогибов ползучести $v_{2}^{0}\left(x_{1}\right)$ для трёхслойных $\left(M^{( \pm)}=1\right.$ ) медных и стальных (рис. 4, а и рис. 5 , а), а также металлокомпозитных (рис. $4, b$ и рис. $5, b$ ) двухопорных (рис. 4) и консольных (рис. 5) балок, рассчитанные (эпюры) при разных значениях интенсивности распределённой нагрузки $q$ с учётом соотношений (17), (18), (21), (22). Сплошные кривые на этих рисунках, номера которых не помечены штрихом, определены на основе теории Тимошенко, а пунктирные линии, номера которых помечены штрихами, - на базе классической теории (в последнем случае в равенствах (5)-(7), (15), (19), (22) следует принять $\left.\xi_{12}^{0}\left(x_{1}\right) \equiv 0\right)$.

Размеры поперечных сечений рассматриваемых трёхслойных балок (рис. 2, b и рис. $2, c$ ) характеризуются следующими значениями:

$$
h_{0}=183.2 \mathrm{MM}, \quad b_{0}=5.2 \mathrm{MM}, \quad h_{1}=h_{-1}=8.4 \mathrm{MM}, \quad b_{1}=b_{-1}=100 \mathrm{MM} .
$$

Эти данные соответствуют характерным значениям размеров двутаврового прокатного профиля № 20 [8].

Кривые $1,1^{\prime}$ и $2,2^{\prime}$ на рис. 4 , а и рис. 5, а рассчитаны для однородных медных и стальных балок соответственно. Линии $1,1^{\prime}$ на рис. 4 , а определены при $q=20 \mathrm{kH} / \mathrm{M}$, а на рис. 5 , а - при $q=5 \mathrm{kH} /$ м; кривые же $2,2^{\prime}$ на рис. 4 , а соответствуют уровню нагрузки $q=630 \mathrm{kH} / \mathrm{m}$, а на рис. 5, a $-q=163 \mathrm{kH} / \mathrm{м}$. При этом точность расчёта податливости по классической теории (см. (25)) для медных (линии 1, $1^{\prime}$ ) двухопорных балок (рис. 4 , а) $\delta v_{2}=8.6 \%$, а для консольных балок (рис. 5, a) $\delta v_{2}=5.1 \%$. В случае же стальных балок (кривые $\left.2,2^{\prime}\right)$ эти величины имеют следующие значения: $\delta v_{2}=1.5 \%$ на рис. 4 , а и $\delta v_{2}=16.7 \%$ на рис. 5 , а. Следовательно, в случае двухопорной медной

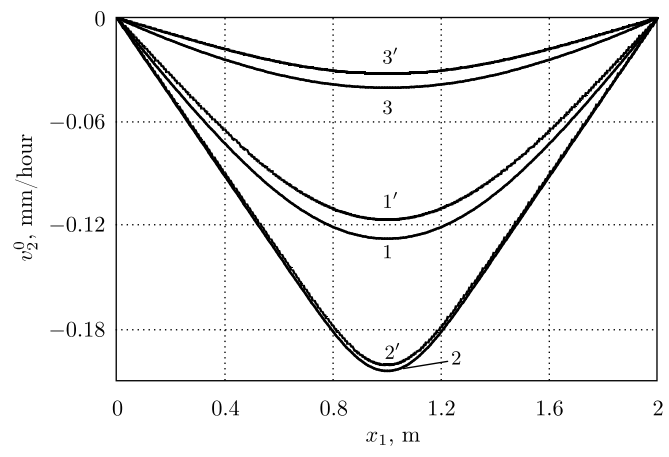

a

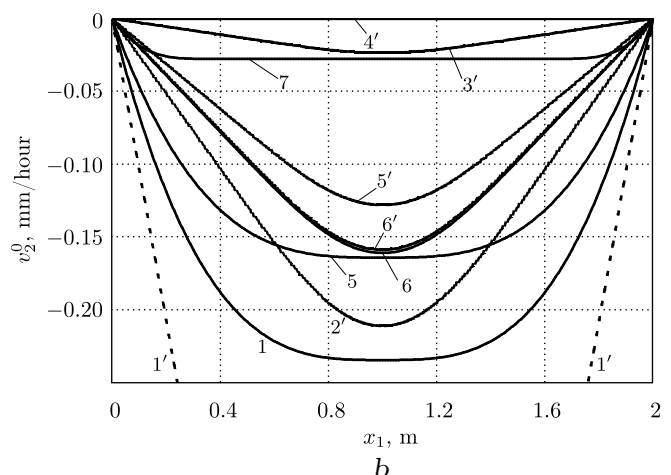

b

Рис. 4. Эпюры скоростей прогибов установившейся ползучести двухопорных балок: а) двутавровых однородных; b)двутавровых металлокомпозитных

[Figure 4. Velocity profile deflection for the pin-ended beams in the case of steady creep, including (a) homogeneous I-beams, (b) layered metal composite I-beams] 

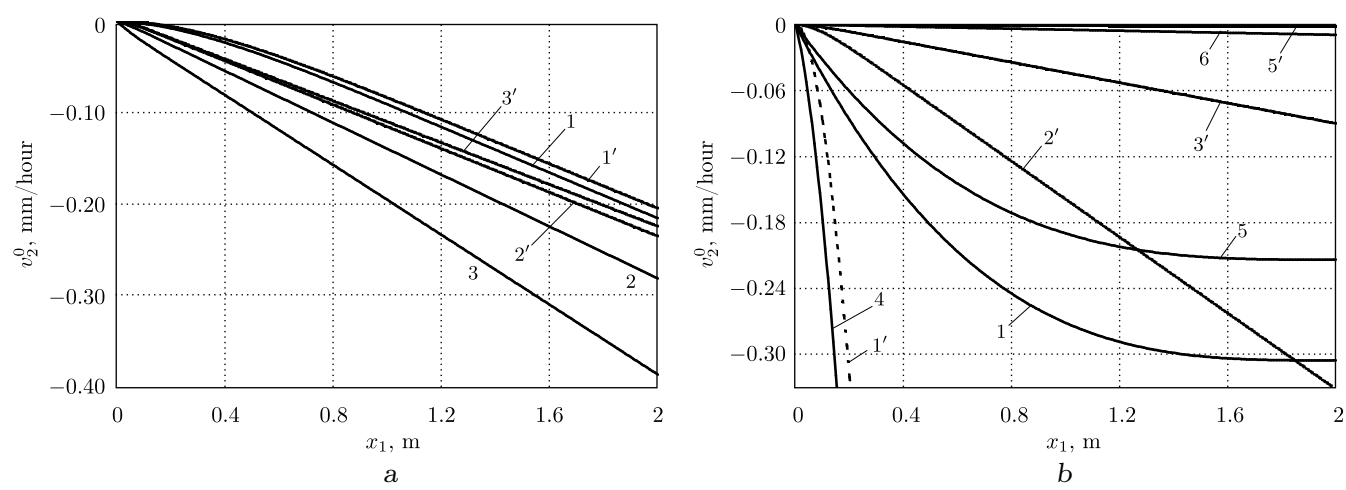

Рис. 5. Эпюры скоростей прогибов установившейся ползучести консольных балок: а) двутавровых однородных; b)двутавровых металлокомпозитных

[Figure 5. Velocity profile deflection for the clamped-free beams in the case of steady creep, including (a) homogeneous I-beams, (b) layered metal composite I-beams]

балки (кривые $1,1^{\prime}$ на рис. 4, а) и консольной стальной балки (линии 2, $2^{\prime}$ на рис. 5, a), выполненных из однородных материалов (рис. 2, b), классическая теория не гарантирует традиционной 5\%-й инженерной точности определения податливости в условиях установившейся ползучести. Если же считать, что $20 \%$-я точность в расчётах на ползучесть вполне приемлема $[4,5,16]$, то, согласно поведению кривых $1,1^{\prime}$ и $2,2^{\prime}$ на рис. 4 , а и рис. 5 , а, с приемлемой точностью расчёт установившейся ползучести изгибаемых однородных балок двутаврового прокатного профиля [8] можно проводить на базе уравнений классической теории. Однако, как показывают дополнительные расчёты, при увеличении размеров несущих слоев (полок) точность классической теории резко падает. Так, кривые $3,3^{\prime}$ на рис. 4 , а и рис. 5 , а рассчитаны для однородных балок, ширина полок которых увеличена вдвое по сравнению со значениями $(26)\left(b_{1}=b_{-1}=200\right.$ мм) и равна высоте балки. Линии $3,3^{\prime}$ на рис. 4 , а определены для медной балки при $q=20 \mathrm{kH} /$ м, и точность классической теории в этом случае характеризуется величиной $\delta v_{2}=20.1 \%$; кривые $3,3^{\prime}$ на рис. 5 , а рассчитаны для стальной балки при $q=290 \mathrm{kH} /$ м и в этом случае $\delta v_{2}=42.1 \%$. Следовательно, даже для однородных балок в рамках 20 \%-й точности расчётов в этих случаях классическая теория не гарантирует получения приемлемых результатов.

Сравнение кривых 1 и 2 на рис. 4, а и рис. 5, а демонстрирует, что при сопоставимой податливости в условиях установившейся ползучести, т. е. при близких по значениям $v_{2}^{*}$ (см. (24)), стальные балки (линии 2) несут более чем в 30 раз большую нагрузку, чем медные (кривые 1), причём массы этих балок примерно равны [15].

Поведение всех кривых на рис. 4, а показывает, что в окрестности центрального сечения двухопорных балок (см. рис. 1 , а при $x_{1}=L / 2$ ) в них реализуется напряжённое состояние, близкое к вязкоползучему шарниру (особенно ярко это проявляется на кривых $2,2^{\prime}$ ). Согласно же поведению кривых $1,1^{\prime}, 2,2^{\prime}$ и $3^{\prime}$ на рис. 5 , а, в случае консольных балок аналогичное напряжённое состояние возникает в окрестности заделки (см. рис. $1, b$ при $\left.x_{1}=0\right)$. Такое поведение эпюр скоростей прогибов ползучести вполне традиционно для однородных балок [4,5]. Однако уже поведение кривой 3 на рис. 5, а отличается от остальных кривых не только количественно, но и качественно. 
Действительно, в окрестности заделки $\left(x_{1} \approx 0\right)$ эта линия имеет кривизну, которая по знаку отлична от кривизны остальных линий на этом рисунке. Такое необычное поведение кривой 3 объясняется тем, что в окрестности заделки в стенке двутавровой стальной балки активно развиваются скорости деформаций поперечного сдвига $\xi_{12}^{0}[9]$. Классическая теория этих скоростей деформаций не учитывает, поэтому-то кривые $3,3^{\prime}$ на рис. 5 , а и различаются столь значительно. Еще в большей степени эффект ослабленного сопротивления стенок слоистых балок поперечным сдвигам в условиях установившейся ползучести проявляется в случаях металлокомпозитных изделий.

На рис. $4, b$ и на рис. $5, b$ изображены эпюры скоростей прогибов $v_{2}^{0}\left(x_{1}\right)$ для металлокомпозитных балок с различными структурами армирования. Композитные балки изготовлены из меди, имеют поперечные сечения в виде двутавра с размерами (26) и армированные несущие слои (рис. 2, с) или армированные несущие слои и стенку, причём стенка может быть усилена в продольном направлении $x_{1}$ (как изображено на рис. 1 , а) или перекрёстно в своей плоскости (как показано на рис. $1, b)$. На рис. $4, b$ все кривые рассчитаны при $q=100 \mathrm{kH} /$ м, на рис. $5, b$ - при $q=41 \mathrm{\kappa H} /$ м.

Традиционно принято считать, что в первую очередь необходимо усиливать несущие слои, поэтому сначала рассмотрим случай армирования только полок медной балки стальной проволокой $\mathrm{Y} 8 \mathrm{~A}\left(K^{(-1)}=K^{(1)}=1\right.$; см. (8)). Обе полки армируются с одинаковой плотностью $\omega_{1}^{(-1)}=\omega_{1}^{(1)}=\omega$. При этом относительное объёмное содержание связующего в несущих слоях определяется из $(8): \omega_{0}^{(-1)}=\omega_{0}^{(1)}=1-\omega\left(\right.$ в стенке же $\left.\omega_{0}^{(0)}=1\right)$.

Расчёты показали, что в случае двухопорной балки (рис. 4, б) при малых значениях плотности армирования полок $\omega \approx 0$ эпюры скоростей прогибов ползучести, рассчитанные по обеим обсуждаемым теориям, качественно подобны кривым 1, $1^{\prime}$ на рис. 4, а, т. е. при достаточно малых значениях $\omega$ в окрестности центрального сечения двухопорной металлокомпозитной балки с армированными несущими слоями возникает напряжённое состояние, близкое к вязкоползучему шарниру. Однако в случае учёта ослабленного сопротивления стенки поперечному сдвигу при некотором предельном значении плотности армирования $\omega_{*}>0$ наблюдается перестройка «механизма» деформирования армированной балки. А именно, при значениях $\omega \geqslant \omega_{*}$ в балке, рассчитанной по теории Тимошенко, деформированное состояние определяется в основном не вязкоползучим шарниром, возникающим в окрестности центрального сечения $\left(x_{1}=L / 2\right)$, а активно развивающимися скоростями деформаций поперечных сдвигов стенки в окрестности опорных сечений $\left(x_{1}=0, L\right)$, причём при $\omega \geqslant \omega_{*}$ эпюра скорости прогиба ползучести $v_{2}^{0}\left(x_{1}\right)$ практически не изменяется (т. е. не зависит от значения параметра $\omega)$.

Так, в рассматриваемом случае в рамках 5\%-й точности для величины $v_{2}^{*}$ (см. (24)) для двухопорной балки указанное предельное значение $\omega_{*}=0.045$. Соответствующая зависимость $v_{2}^{0}\left(x_{1}\right)$ на рис. $4, b$ характеризуется кривой 1. При $\omega>\omega_{*}=0.045$ графики зависимостей $v_{2}^{0}\left(x_{1}\right)$, рассчитанных по теории Тимошенко, практически не отличаются от кривой 1 , т. е. при $\omega>\omega_{*}$ наблюдается эффект «переармирования», когда увеличение объёма арматуры в конструкции практически не влияет на её механическое поведение в условиях установившейся ползучести. Расчёты же, выполненные по классической теории, показывают, что эффект «переармирования» не наблюдается, т. е. 
в рамках этой теории получается традиционный результат: чем больше используется арматуры при усилении несущих слоев, тем меньше податливость балки в условиях установившейся ползучести. Так, кривые $1^{\prime}, 2^{\prime}, 3^{\prime}$ и $4^{\prime}$ на рис. $4, b$ рассчитаны по теории Бернулли при значениях $\omega=0.1, \omega=0.15$, $\omega=0.2$ и $\omega=0.3$ соответственно. Кривая $4^{\prime}$ визуально не отличается от горизонтальной линии, так как ординаты её точек на 4 порядка меньше, чем ординаты точек на кривой 1, определённой по теории Тимошенко (и практически неотличимой от аналогичной кривой, рассчитанной при $\omega=0.3)$. Следовательно, согласно поведению линии $4^{\prime}$ на рис. $4, b$, при относительном объёмном содержании волокон в полках $\omega \geqslant 0.3$ как бы наблюдается эффект «абсолютного армирования» в том смысле, что классическая теория предсказывает практически полное отсутствие ползучести металлокомпозитных балок при заданном уровне их нагружения $(q=100 \mathrm{kH} / \mathrm{m})$. Однако поведение кривой 1 , рассчитанной с учётом ослабленного сопротивления стенок этих балок поперечным сдвигам, показывает, что при $\omega>\omega_{*}=0.045$ (в том числе и при $\omega \geqslant 0.3)$ металлокомпозитные конструкции всё же ползут, причём достаточно интенсивно.

Из сравнения кривых 1 на рис. 4, а и рис. 4, b видно, что примерно при одинаковой податливости (значение величины $v_{2}^{*}$ (см. (24)) для кривой 1 на рис. $4, b$ лишь в два раза больше аналогичной величины для кривой 1 на рис. 4 , а) металлокомпозитная балка несёт в пять раз большую нагрузку, чем однородная медная, т. е. действительно имеет место эффект армирования (даже при достаточно малых плотностях армирования полок $\left.\omega=\omega_{*}=0.045\right)$, но этот эффект не является «абсолютным», как то предсказывает классическая теория при $\omega \geqslant 0.3$.

Поведение же кривой $1^{\prime}$ на рис. $4, b$, для которой значение $v_{2}^{*}=0.803 \mathrm{Mm} /$ ч (поэтому линия $1^{\prime}$ на рис. $4, b$ изображена не полностью), свидетельствует о том, что при малых плотностях армирования (напомним, кривая 1' рассчитана при $\omega=0.1$ ) податливость металлокомпозитных балок в условиях установившейся ползучести, предсказываемая классической теорией, оказывается большей, чем при расчётах по теории Тимошенко (см. кривую 1 на рис. $4, b$, которая характеризует эпюру скорости прогибов при $\omega \geqslant \omega_{*}=$ $=0.045)$.

Этот результат противоречит традиционным представлениям, согласно которым учёт ослабленного сопротивления поперечным сдвигам приводит к увеличению расчётной податливости исследуемых изгибаемых тонкостенных конструкций, как это имеет место, например, на рис. 4, а. Парадоксальный, на первый взгляд, результат, связанный с тем, что кривая $1^{\prime}$ на рис. $4, b$ лежит ниже линии 1 , объясняется следующим. Как уже отмечалось, в рамках расчётов по классической теории деформирование двухопорных балок (в том числе и металлокомпозитных) происходит как бы с образованием вязкоползучего шарнира в центральном сечении $x_{1}=L / 2$ (см., например, кривую $2^{\prime}$ на рис. $4, b)$, т. е. в рамках теории Бернулли в условиях установившейся ползучести балка работает подобно механизму с вязким шарниром в центральном сечении, поэтому при достаточно малых плотностях армирования полок $(0.036 \leqslant \omega<0.147)$ скорости прогиба, рассчитанные по классической теории, в центральном сечении по модулю оказываются большими, чем при расчётах по теории Тимошенко, так как в рамках последней теории при $\omega \geqslant 0.045$ 
реализуется совсем другой «механизм» деформирования балок, связанный с активным развитием скоростей деформаций поперечных сдвигов стенки в окрестности опорных сечений $x_{1}=\{0, L\}$, а не с образованием вязкоползучего шарнира в окрестности центрального сечения $x_{1}=L / 2$.

Таким образом, согласно расчётам, проведённым в уточнённой постановке (в рамках теории Тимошенко), нет смысла армировать несущие слои рассматриваемой металлокомпозитной балки с плотностью $\omega$, большей предельного значения $\omega_{*}=0.045$, так как при $\omega>\omega_{*}$ податливость такой конструкции, работающей в условиях установившейся ползучести, практически не изменяется, а зависимость $v_{2}^{0}\left(x_{1}\right)$ в пределах $5 \%$-й точности характеризуется кривой 1 на рис. $4, b$. Следовательно, для дальнейшего увеличения сопротивляемости металлокомпозитной балки остаётся только один путь (без изменения её габаритов и геометрии) - это армирование стенки.

Предположим, что несущие слои балки по-прежнему армированы одинаково $\left(\omega_{1}^{(-1)}=\omega_{1}^{(1)}=\omega\right)$, а стенка усилена только одним семейством проволок У8А $\left(K^{(0)}=1\right)$ в продольном направлении $x_{1}$ (т. е. $\varphi_{1}=0$; см. рис. 1 , а и рис. 3) с плотностью армирования $\omega_{1}^{(0)}>0$. Расчёты показали, что в этом случае при фиксированном значении $\omega$ увеличение плотности армирования стенки $\omega_{1}^{(0)}$ приводит к монотонному уменьшению величины $v_{2}^{*}($ см. $(24))$, т. е. к монотонному уменьшению податливости металлокомпозитной балки в условиях установившейся ползучести. Так, кривая 5 на рис. $4, b$ рассчитана по теории Тимошенко при значениях $\omega=\omega_{*}=0.045$ и $\omega_{1}^{(0)}=0.3$. Дополнительные расчёты показали, что при $\omega>\omega_{*}$ и $\omega_{1}^{(0)}=0.3$ графики зависимостей $v_{2}^{0}\left(x_{1}\right)$ практически не отличаются от кривой 5 на рис. $4, b$, т. е. в рамках теории Тимошенко и при $\omega_{1}^{(0)}>0$ наблюдается эффект «переармирования» полок. Расчёты, проведённые по классической теории, демонстрируют, что при $\omega_{1}^{(0)}>0$, как и в случае неармированной стенки $\left(\omega_{1}^{(0)}=0\right)$, эффект «переармирования» полок трёхслойной балки не наблюдается. Например, при $\omega=0.08$ и $\omega_{1}^{(0)}=0.3$ эпюра скорости прогиба, рассчитанная по теории Бернулли, характеризуется кривой $5^{\prime}$ на рис. $4, b$, а при $\omega=0.3$ и $\omega_{1}^{(0)}=0.3$ величина $v_{2}^{*}$ (см. (24)), определённая по классической теории, на 7 порядков меньше аналогичной величины для кривой $5^{\prime}$, поэтому соответствующая эпюра скорости прогибов на рис. $4, b$ визуально не отличается от горизонтальной линии $4^{\prime}$, т. е. и в этом случае (при $\omega \geqslant 0.3$ и $\omega_{1}^{(0)}=0.3$ ) в рамках расчётов по классической теории наблюдается как бы эффект «абсолютного армирования».

Поведение кривых 1 и 5 на рис. $4, b$ показывает, что в рамках теории Тимошенко в металлокомпозитных балках обнаруживаются краевые эффекты, которые с увеличением плотности армирования стенки (с увеличением $\left.\omega_{1}^{(0)}\right)$ проявляются все более ярко (например, центральная часть кривой 5 на рис. 4, b практически горизонтальна). Эти краевые эффекты являются следствием того, что в условиях установившейся ползучести в окрестности опорных сечений в стенках металлокомпозитных балок активно развиваются скорости деформаций поперечных сдвигов, которые классическая теория не учитывает. При этом следует отметить, что при продольном армировании 
стенки (при $\left.\omega_{1}^{(0)}>0\right)$ скорости деформаций поперечных сдвигов развиваются в основном в связующем материале стенки и их величина по модулю тем больше, чем больше плотность армирования стенки $\omega_{1}^{(0)}$, поэтому-то с увеличением $\omega_{1}^{(0)}$ более ярко проявляются краевые эффекты в металлокомпозитных балках, хотя их податливость и уменьшается.

Для исключения возможности активного развития скоростей деформаций поперечных сдвигов в стенке необходимо её армировать перекрёстно (как показано на рис. $1, b)$, а не продольно (как изображено на рис. 1, a). Для демонстрации этого факта рассмотрим трёхслойную металлокомпозитную балку прежних размеров (см. (26)), несущие слои которой по-прежнему армированы в продольном направлении с одинаковой плотностью $\omega_{1}^{(-1)}=\omega_{1}^{(1)}=\omega$, а стенка перекрёстно армирована двумя $\left(K^{(0)}=2\right)$ семействами проволок У8А с одинаковой плотностью $\omega_{1}^{(0)}=\omega_{2}^{(0)}>0$ по направлениям $\varphi_{1}=-\varphi_{2}=\pi / 4$ (см. рис. 3) - ортогональное армирование (см. рис. 1, b).

Рассмотрим случай, когда в перекрёстно армированной стенке

$$
\omega_{1}^{(0)}=\omega_{2}^{(0)}=0.15
$$

При этом суммарная плотность армирования стенки $\left(\omega_{1}^{(0)}+\omega_{2}^{(0)}=0.3\right)$ и общий расход арматуры в стенке такие же, как и в ранее исследованном случае продольного армирования стенки. Кривые 6 и $6^{\prime}$ на рис. $4, b$ рассчитаны при плотности армирования полок $\omega=0.12$, причём для этих зависимостей $v_{2}^{0}\left(x_{1}\right)$ величина $\delta v_{2}=1.2 \%$ (см. (25)), т. е. при заданных значениях $\omega_{1}^{(0)}=\omega_{2}^{(0)}$ классическая теория с приемлемой точностью описывает податливость такой металлокомпозитной балки в условиях установившейся ползучести.

Поведение же кривых $6,6^{\prime}$ на рис. $4, b$ показывает, что при перекрёстном армировании стенки «механизм» деформирования исследуемой балки в рамках обеих сравниваемых теорий такой же, как в однородных конструкциях (см. кривые 2, 2' на рис. 4, а), т. е. в окрестности центрального сечения $x_{1}=L / 2$ в металлокомпозитной балке возникает напряженное состояние, близкое к вязкоползучему шарниру, а скорости деформаций поперечного сдвига в окрестности опорных сечений $x_{1}=\{0, L\}$ в стенке практически не развиваются.

Дополнительные расчёты показали, что увеличение плотности армирования полок $(\omega>0.12)$ приводит к значительному уменьшению величин $v_{2}^{*}$ (см. (24)), рассчитанных по обеим обсуждаемым теориям. Так, при $\omega=0.3$ значения $v_{2}^{*}$ на 6 порядков меньше аналогичных величин, соответствующих кривым $6,6^{\prime}$ на рис. $4, b$. Следовательно, при перекрёстном армировании стенки с плотностями $\omega_{1}^{(0)}=\omega_{2}^{(0)}=0.15$ в рамках теории Тимошенко уже не наблюдается эффект «переармирования» полок, как это имело место выше в случаях, соответствующих кривым 1 и 5 на рис. 4, b. Кроме того, при плотностях армирования полок $\omega \geqslant 0.3$ наблюдается эффект как бы «абсолютного упрочнения» рассматриваемой балки в том смысле, что при $\omega \geqslant 0.3$ такая балка практически не ползет при заданном уровне внешней нагрузки $q=100 \mathrm{kH} / \mathrm{M}$.

Напомним, что кривая 5 на рис. 4 , b была получена для металлокомпозитных балок, стенка которых армирована в продольном направлении с плот- 
ностью $\omega_{1}^{(0)}=0.3$, а полки усилены стальной проволокой У8А с интенсивностью $\omega \geqslant 0.045$. Расчёты же балки с перекрёстным армированием стенки $\left(\omega_{1}^{(0)}=\omega_{2}^{(0)}=0.15\right)$ показали, что при усилении полок с плотностями армирования $0.045 \leqslant \omega<0.12$ значения величин $v_{2}^{*}$ (см. (24)) оказываются большими, чем аналогичная величина, соответствующая кривой 5 на рис. $4, b$. Следовательно, при армировании полок с плотностью, лежащей в диапазоне $0.045 \leqslant \omega<0.12$, балка с перекрёстно армированной стенкой оказывается более податливой в условиях установившейся ползучести, чем аналогичная конструкция с продольным армированием стенки.

Эти результаты показывают, что для получения рациональных или оптимальных проектов композитных балок слоисто-волокнистой структуры целевое управление необходимо осуществлять не только за счёт варьирования структуры армирования несущих слоев (полок) или стенки по отдельности, но и за счёт одновременного управления этими структурами.

Как было показано выше (см. кривые $6,6^{\prime}$ на рис. $\left.4, b\right)$, при перекрёстном армировании стенки в случае $\omega_{1}^{(0)}=\omega_{2}^{(0)}=0.15$ классическая теория обеспечивает вполне приемлемую точность расчёта податливости рассматриваемой металлокомпозитной балки, работающей в условиях установившейся ползучести. Однако при достаточно малых плотностях армирования стенки $\left(\omega_{1}^{(0)}=\right.$ $=\omega_{2}^{(0)} \approx 0$ ) разность решений, полученных в рамках классической теории и теории Тимошенко, может стать значительной. Так, при плотностях армирования полок $\omega=0.12$ (это значение соответствует кривым $6,6^{\prime}$ на рис. $4, b$ при $\omega_{1}^{(0)}=\omega_{2}^{(0)}=0.15$ ) значение относительной величины $\delta v_{2} \geqslant 5 \%$ (см. (25)) при интенсивностях армирования стенки $\omega_{1}^{(0)}=\omega_{2}^{(0)} \leqslant 0.057$, а $\delta v_{2} \geqslant 20 \%$ при $\omega_{1}^{(0)}=\omega_{2}^{(0)} \leqslant 0.0224$.

Кроме того, при $\omega_{1}^{(0)}=\omega_{2}^{(0)} \leqslant 0.022$ точность решения, полученного по классической теории, резко падает, так как в рамках расчётов по теории Тимошенко происходит смена «механизма» деформирования рассматриваемой балки. Если при $\omega_{1}^{(0)}=\omega_{2}^{(0)}>0.022$, согласно теории Тимошенко, балка деформируется как бы с образованием вязкоползучего шарнира в окрестности центрального сечения $x_{1}=L / 2$ (график зависимости $v_{2}^{0}\left(x_{1}\right)$ при этом качественно подобен кривой 6 на рис. $4, b)$, то при $\omega_{1}^{(0)}=\omega_{2}^{(0)} \leqslant 0.022$ «механизм» деформирования балки определяется активно развивающимися скоростями деформаций поперечного сдвига стенки. Так, кривая 7 на рис. 4, b рассчитана по теории Тимошенко для балки, стенка которой перекрёстно армирована с плотностями $\omega_{1}^{(0)}=\omega_{2}^{(0)}=0.02$. Поведение этой кривой свидетельствует о появлении в окрестности опорных сечений $x_{1}=\{0, L\}$ ярко выраженных краевых эффектов. Аналогичная кривая, рассчитанная по теории Бернулли, на рис. $4, b$ не приведена, так как для неё величина $v_{2}^{*}=0.443 \mathrm{Mм} /$ ч (см. (24)), что в 16 раз больше такой же величины для кривой 7. Сопоставление же кривых 6 и 7 на рис. $4, b$ показывает, что величина $v_{2}^{*}$ для кривой 6 в 5.8 раз больше аналогичной величины для кривой 7 , при этом обе кривые соответствуют балкам, в которых стенки армированы перекрёстно, но в случае балки, которой соответствует кривая 7, расход арматуры в стенке в 7.5 раз меньше, чем в случае, соответствующем кривой 6 (расход же арматуры в пол- 
ках обеих конструкций одинаков). Следовательно, при перекрёстном армировании стенки также наблюдается эффект «переармирования», причём более ярко, чем ранее (в случае «переармирования» полок), так как при увеличении плотностей армирования стенки (при $\left.\omega_{1}^{(0)}=\omega_{2}^{(0)}>0.022\right)$ наблюдается увеличение податливости металлокомпозитной конструкции (см. переход от кривой 7 к линии 6 на рис. $4, b)$.

Таким образом, даже при перекрёстном армировании стенки классическая теория не всегда обеспечивает приемлемую точность расчёта податливости металлокомпозитных балок, работающих в условиях установившейся ползучести.

Для консольных металлокомпозитных балок (см. рис. 1, b) получаются результаты, качественно аналогичные тем, что изложены выше, поэтому лишь кратко остановимся на их описании. На рис. $5, b$ изображены графики зависимостей $v_{2}^{0}\left(x_{1}\right)$ для консольных композитных балок прежних размеров (см. (26)), рассчитанные при интенсивности внешней распределенной нагрузки $q=41 \mathrm{\kappa H} / \mathrm{\text {м. }}$

При армировании только полок $\left(\omega_{0}^{(0)}=1\right.$; см. (8)) медных консольных балок с одинаковыми плотностями $\omega_{1}^{(-1)}=\omega_{1}^{(1)}=\omega>0$ в рамках расчётов по теории Тимошенко также наблюдается эффект «переармирования», т. е. при $\omega \geqslant \omega_{*}$ эпюры скоростей прогибов ползучести $v_{2}^{0}\left(x_{1}\right)$ практически не зависят от значений параметра $\omega$. В рамках $5 \%$-й точности расчёта величины $v_{2}^{*}$ (см. (24)) предельное значение плотности армирования полок $\omega_{*}$ для консольной балки равно 0.07 .

Кривая 1 на рис. 5, $b$ рассчитана при этом значении $\omega=\omega_{*}=0.07$. В рамках же расчёта по теории Бернулли эффект «переармирования» полок по-прежнему не наблюдается, т. е. с увеличением значения $\omega$ монотонно уменьшается величина $v_{2}^{*}$, а значит, уменьшается и податливость балки в условиях установившейся ползучести. Так, кривые $1^{\prime}$ (для этой кривой значение $v_{2}^{*}=9.45 \mathrm{~mm} /$ ч), $2^{\prime}$ и $3^{\prime}$ на рис. $5, b$ определены по классической теории при значениях плотности армирования полок $\omega=0.071, \omega=0.26, \omega=0.3$ соответственно, а при $\omega=0.35$ значение $v_{2}^{*}=0.0104 \mathrm{Mm} /$, т. е. соответствующая эпюра $v_{2}^{0}\left(x_{1}\right)$ почти не отличается от линии $5^{\prime}$ и на рис. $5, b$ не изображена.

При расчётах консольной балки с армированными полками в рамках теории Тимошенко было обнаружено, что в диапазоне $0.059 \leqslant \omega \leqslant 0.111$ существуют два решения рассматриваемой задачи, одно из которых условно можно назвать «классическим», а второе «неклассическим». Первое решение характеризуется тем, что ему соответствует «механизм» деформирования балки такой же, как в рамках расчётов по классической теории Бернулли, т. е. как бы с образованием вязкоползучего шарнира в окрестности жёстко закреплённого сечения $x_{1}=0$ (как на рис. 5, а). Неклассическое же решение характеризуется другим «механизмом» деформирования, а именно, активным развитием скоростей деформаций поперечного сдвига стенки в окрестности опорного сечения. Так, кривая 1 на рис. 5, b рассчитана при $\omega=0.07$ и соответствует «неклассическому» решению, а линия 4 определена при $\omega=0.071$ и характеризует «классическое» решение (для этой кривой значение $v_{2}^{*}=1.04 \mathrm{~cm} /$ ч, что в 35 раз больше аналогичной величины для кривой 1). Линии 4 и $1^{\prime}$ на рис. 5, л лежат достаточно близко: для этих кривых 
величина $\delta v_{2}=9.1 \%$ (см. (25)). Следовательно, при одной и той же плотности армирования полок $\omega=0.071$ теория Бернулли даёт решение, близкое к «классическому» решению, определённому в рамках теории Тимошенко. Неклассическое же решение (кривая 1) существенно отличается как качественно, так и количественно от решения, построенного на базе уравнений теории Бернулли (кривая $\left.1^{\prime}\right)$.

Возможность существования двух альтернативных решений прямой задачи расчёта установившейся ползучести изгибаемых металлокомпозитных балок является следствием нелинейности системы разрешающих уравнений (15). Действительно, если в (15) все производные от неизвестных функций заменить конечными разностями, то после соответствующей дискретизации рассматриваемой задачи вместо системы (15) с учётом (23) получим её нелинейный конечно-разностный аналог, содержащий в качестве неизвестных узловые значения разыскиваемых функций $v_{1}^{0}, v_{2}^{0}, \xi_{12}^{0}$. Так как в общем случае системы нелинейных (трансцендентных) уравнений могут иметь несколько решений, рассматриваемая задача изгиба консольных балок, работающих в условиях установившейся ползучести, в определённом диапазоне изменения плотностей армирования полок допускает возможность существования двух альтернативных решений: «классического» и «неклассического».

На практике реализация того или иного типа решения, по-видимому, будет определяться наличием каких-либо начальных несовершенств (например, начальным напряжённо-деформированным состоянием в балке, которое в настоящем исследовании не учитывается), как это имеет место в нелинейных задачах устойчивости тонкостенных элементов конструкций, когда особенности их закритического поведения определяются несовершенством геометрии - начальной погибью [17]. В проведённых же расчётах в качестве таких «начальных несовершенств» выступают начальные приближения для решения, разыскиваемого методом простой итерации (см. (19)). Так, кривая 1 на рис. $5, b$ определена при $\omega=0.07$, а линия $4-$ при $\omega=0.071$, а значит, и начальные приближения в соответствующих расчётах, хоть и близки, всё же различаются, что и приводит к тому, что итерационный процесс сходится к совершенно разным решениям: «классическому» (кривая 4) и «неклассическому» (кривая 1).

Насколько известно автору, в настоящем исследовании впервые удалось обнаружить неединственность решения прямой задачи расчёта установившейся ползучести изгибаемых тонкостенных элементов конструкций. Ранее неединственность решения в задачах ползучести таких конструкций была выявлена в [18], где на основе модели жёсткоползучего тела [4] исследовалась проблема определения предельных уровней нагружения армированных металлокомпозитных оболочек. При этом было обнаружено, что при некоторых структурах армирования в предельном состоянии могут реализоваться два совершенно разных «механизма» деформирования тонкостенной конструкции, приводящие к одному и тому же значению предельной нагрузки. Здесь же уместно напомнить, что модель жёсткоползучего тела может рассматриваться как предельный случай, когда в степенном законе установившейся ползучести показатели $\mu_{k}^{(m)} \rightarrow \infty($ см. (23)) [4], поэтому полученный в настоящем исследовании необычный на первый взгляд результат, касающийся неединственности решения прямой задачи об установившейся ползучести 
изгибаемых металлокомпозитных балок, вполне согласуется с ранее полученными в предельном случае результатами [18].

Как и в случае двухопорных балок, значительного уменьшения податливости в условиях установившейся ползучести металлокомпозитных конструкций можно добиться не столько за счёт армирования полок, сколько за счёт совместного усиления и полок, и стенок рассматриваемых консольных балок.

Так, кривая 5 на рис. 5 , b получена на основе теории Тимошенко при продольном армировании стенки в направлении $x_{1}$ (как изображено на рис. $\left.1, \mathrm{a}\right)$ с плотностью $\omega_{1}^{(0)}=0.3$ и одновременном армировании полок с интенсивностями $\omega_{1}^{(-1)}=\omega_{1}^{(1)}=\omega=0.07$. Варьирование величины $\omega$ при фиксированной плотности армирования стенки $\omega_{1}^{(0)}$ показало, что и в этом случае наблюдается эффект «переармирования» полок, т. е. при $\omega \geqslant \omega_{*}$ эпюры скоростей прогибов ползучести $v_{2}^{0}\left(x_{1}\right)$ практически не зависят от изменения значений параметра $\omega$. В рамках 5 \%-й точности определения величины $v_{2}^{*}$ (см. (24)) здесь, как и в случае кривой 1 на рис. $5, b$, предельное значение плотности армирования полок $\omega_{*}=0.07$.

Расчёты же, проведённые по классической теории, показали, что при продольном армировании стенки эффект «переармирования» полок по-прежнему не наблюдается. Так, кривая $5^{\prime}$ на рис. 5, b получена по теории Бернулли при $\omega_{1}^{(0)}=0.3$ и $\omega=0.3$. Соответствующая кривая, определённая по теории Тимошенко, практически совпадает с линией 5 на рис. $5, b$. При этом точность классической теории определяется значением величины $\delta v_{2}=99.1 \%$ (см. (25)).

Дальнейшего уменьшения податливости консольной балки при фиксированном расходе арматуры в стенке можно добиться за счёт перекрёстного (как показано на рис. 1, b), а не продольного армирования стенки. Так, кривая 6 на рис. 5, b рассчитана по теории Тимошенко при перекрёстном армировании стенки с одинаковой плотностью $\omega_{1}^{(0)}=\omega_{2}^{(0)}=0.15$ по направлениям $\varphi_{1}=-\varphi_{2}=\pi / 4$ (ортогональное армирование), а также при армировании полок с интенсивностью $\omega_{1}^{(-1)}=\omega_{1}^{(1)}=0.3$. Напомним, что при продольном армировании стенки с тем же расходом арматуры во всех слоях балки $\left(\omega_{1}^{(0)}=0.3, \omega_{1}^{(-1)}=\omega_{1}^{(1)}=0.3\right)$ зависимость $v_{2}^{0}\left(x_{1}\right)$ характеризуется кривой 5 на рис. $5, b$. Сравнение кривых 5 и 6 на рис. $5, b$ демонстрирует эффект значительного усиления стенки за счёт её перекрёстного армирования по сравнению со случаем продольного армирования.

Поведение кривой 6 качественно подобно поведению зависимостей $v_{2}^{0}\left(x_{1}\right)$, рассчитанных для консольной балки по классической теории (см., например, кривую $3^{\prime}$ на рис. $\left.5, b\right)$, и принципиально отличается от поведения кривых 1 и 5 , а именно, линия 6 имеет по сравнению с линиями 1 и 5 кривизну другого знака. Знак кривизны линий 1 и 5 определяется тем, что в окрестности заделки $\left(x_{1} \approx 0\right)$ в стенках соответствующих балок активно развиваются скорости деформаций поперечных сдвигов, а знак кривизны линии 6 определяется тем, что в окрестности заделки в балке с перекрёстно армированной стенкой возникает напряжённое состояние, близкое к вязкоползучему шарниру.

Поведение кривых 1 и 5 на рис. 5, b свидетельствует о том, что в соответствующих консольных балках в окрестности опорного сечения $\left(x_{1} \approx 0\right)$ возникают краевые эффекты, которые проявляются тем ярче, чем больше 
плотность армирования стенки в продольном направлении (т. е. чем больше величина $\left.\omega_{1}^{(0)}\right)$.

В случае перекрёстного армирования стенки неединственность решения рассматриваемой задачи не проявилась, а в случае продольного армирования неединственность решения была обнаружена лишь при достаточно малых значениях плотностей армирования стенки: $\omega_{1}^{(0)} \leqslant 0.057$.

В завершение настоящего раздела отметим, что результаты, качественно аналогичные тем, что изложены выше, получаются и в тех случаях, когда вместо усиления полок армирующими волокнами используется усиление конструкции за счёт дополнительных изотропных стальных слоёв, т. е. когда, например, вместо трёхслойного стержня, поперечное сечение которого изображено на рис. 2, с, используется пятислойный стержень $\left(M^{( \pm)}=2\right)$, причём три внутренних слоя образуют двутавровую медную балку (возможно, с армированной стенкой), к несущим слоям которой сверху и снизу прикреплены изотропные слои из стали марки У8А (см. рис. $2, d)$. В этом случае изменение площадей поперечных сечений внешних стальных слоев $S_{-2}, S_{2}$ (см. (16)) играет роль, аналогичную изменению плотностей армирования полок $\omega_{1}^{(-1)}$, $\omega_{1}^{(1)}$ в вышеприведённых исследованиях.

Заключение. Проведённый сравнительный анализ результатов расчётов, выполненных в рамках двух теорий деформирования изгибаемых металлокомпозитных балок слоисто-волокнистой структуры, работающих в условиях установившейся ползучести, показал, что классическая теория Бернулли в случае металлокомпозитных конструкций может приводить к совершенно неприемлемым результатам, занижая их податливость на несколько порядков. Кроме того, классическая теория может приводить к неприемлемым результатам даже для однородных металлокомпозитных балок, имеющих достаточно широкие несущие слои (например, в случаях, когда в балках двутаврового поперечного сечения ширина полок равна высоте поперечного сечения). В силу этих обстоятельств для получения адекватных результатов расчётов изгибного деформирования металлокомпозитных балок, работающих в условиях установившейся ползучести, целесообразно использовать неклассическую теорию Тимошенко, в рамках которой учитывается ослабленное сопротивление стенок таких балок поперечному сдвигу. Расчёты, проведённые по теории Тимошенко, позволили выявить такие эффекты, как «переармирование» несущих слоев (полок) и стенки (в случае её перекрёстного армирования), а также возможность существования двух альтернативных решений рассматриваемой задачи в некоторых диапазонах изменения плотностей армирования полок и стенок. Согласно первому из этих решений, в балке реализуется такой же «механизм» её деформирования, какой предсказывает и классическая теория, т. е. в окрестности некоторых сечений возникает напряжённое состояние, близкое к вязкоползучему шарниру. Согласно же второму решению, в балке реализуется совершенно другой «механизм» её деформирования, связанный с активным развитием в стенке скоростей деформаций поперечного сдвига в окрестности опорных сечений. Этот тип решения классическая теория вообще не выявляет. Эффекты «переармирования» как раз и связаны со сменой типа решения, когда при плотностях армирования, превышающих некоторые предельные значения, решение «классическо- 
го» типа сменяется решением «неклассического» типа и наоборот. В решениях «неклассического» типа возникают ярко выраженные краевые эффекты, которые не имеют места в решениях, полученных в рамках классической теории.

Благодарности. Работа выполнена при поддержке Российского фонда фундаментальных исследований (проект № 14-01-00102-а).

\section{ORCID}

Андрей Петрович Янковский: http://orcid.org/0000-0002-2602-8357

\section{БИБЛИОГРАФИЧЕСКИЙ СПИСОК}

1. Каркаускас Р. П., Крутинис А. А., Аткочюнас Ю. Ю., Каланта С. А., Нагявичюс Ю. А. Строительная механика. Программы и решения задач на ЭВМ/ ред. А. А. Чираса. М.: Стройиздат, 1990. 360 с.

2. Немировский Ю. В., Мищенко А. В., Вохмянин И. Т. Рациональное и оптималъное проектирование слоистых стержневых систем. Новосибирск: НГАСУ, 2004. 488 с.

3. Композиционные материалы: Справочник/ ред. В. В. Васильев, Ю. М. Тарнопольский. М.: Машиностроение, 1990. 512 с.

4. Качанов Л. М. Теория ползучести. М.: Физматгиз, 1960. 456 с.

5. Работнов Ю. Н. Ползучесть элементов конструкиий. М.: Наука, 1966. 752 с.

6. Радченко В. П., Еремин Ю. А. Реологическое деформирование и разрушение материалов и элементов конструкиий. М.: Машиностроение-1, 2004. 264 с.

7. Мищенко А. В., Немировский Ю. В. Ползучесть однородных и слоистых рам на основе трехкомпонентной модели // Изв. вузов. Строительство, 2009. № 5. С. 16-24.

8. Феодосьев В. И. Сопротивление материалов. М.: Наука, 1986. 512 с.

9. Янковский А. П. Исследование установившейся ползучести армированных металлокомпозитных балок-стенок с учётом ослабленного сопротивления поперечному сдвигу // Механика композиционных материалов и конструкиий, 2012. Т. 18, № 3. С. 301319.

10. Юзиков В. П., Панасенко Н. Н. Строительная механика тонкостенных стержней. Волгоград: Волгоград. научн. изд-во, 2013. 361 с.

11. Васильев В. В. Механика конструкций из композиционных материалов. М.: Машиностроение, 1988. 272 с.

12. Washizu K. Variational Methods in Elasticity and Plasticity. New York: Pergamon Press, 1982. xv+630 pp.

13. Янковский А. П. Моделирование механического поведения перекрёстно армированных металлокомпозитов в условиях установившейся ползучести // Механика композиционных материалов и конструкиий, 2011. Т. 17, № 3. С. 362-384.

14. Писаренко Г. С., Можаровский Н. С. Уравнения и краевые задачи теории пластичности и ползучести. Справочное пособие. Киев: Наукова думка, 1981. 496 с.

15. Композииионные материалы: Справочник/ ред. Д. М. Карпинос. Киев: Наукова думка, 1985. 592 с.

16. Никитенко А. Ф. Ползучесть и длительная прочность металлических материалов. Новосибирск: НГАСУ, 1997. 278 с.

17. Перельмутер А. В., Сливкер В. И. Устойчивость равновесия конструкиий и родственные проблемы. Т. 3. М.: СКАД СОФТ, 2011. 400 с.

18. Янковский А. П. Оценка предельных уровней нагружения сложно армированных оболочек вращения в условиях ползучести // Проблемы прочности и пластичности, 2010. № 72. С. $63-72$. 
Vestn. Samar. Gos. Techn. Un-ta. Ser. Fiz.-mat. nauki

[J. Samara State Tech. Univ., Ser. Phys. \& Math. Sci.], 2016, vol. 20, no. 1, pp. 85-108

ISSN: 2310-7081 (online), 1991-8615 (print)

doi: http://dx.doi.org/10.14498/vsgtu1459

MSC: 74K20, 74R20

\title{
A STUDY OF STEADY CREEP OF LAYERED METAL-COMPOSITE BEAMS OF LAMINATED-FIBROUS STRUCTURES WITH ACCOUNT OF THEIR WEAKENED RESISTANCE TO THE TRANSVERSE SHIFT
}

\section{A. P. Yankovskii}

Khristianovich Institute of Theoretical and Applied Mechanics, Siberian Branch of the Russian Academy of Sciences,

4/1, Institutskaya st., Novosibirsk, 630090, Russian Federation.

\begin{abstract}
Steady-state creep of a hybrid metal-composite laminated bending beams of irregular patterns is considered. Beams consist of walls and load-bearing layers, attached at the top and bottom (shelves). The shelves are reinforced with fibers in the longitudinal direction, and the walls are reinforced either longitudinally or cross in the plane. Under the hypotheses of the Timoshenko theory the boundary value problem is formulated for the calculation of the considered beams, which allows taking into account the weakened resistance of the walls of the transverse shifts. The simple iteration method based on the idea of the se-cant modulus method is applied for linearization of the problem. The mechani-cal behavior of reinforced and unreinforced doubleseat beams and cantilevers in conditions of steady creep under the action of uniformly distributed trans-verse load is investigated. Cross sections of beams are I-shaped. It is shown that for homogeneous I-beams, the classical Bernoulli theory does not guaran-tee the calculated results in compliance within $20 \%$ accuracy, which is consid-ered to be acceptable if the width of the shelf is comparable with the height of cross sections of beams. In the cases of metal-composite beams, the classical theory becomes generally unacceptable, because it lowers by several orders of magnitude the compliance of such structures in conditions of steady creep. It is demonstrated that the rate of shear strain, actively developing in their walls, must be considered. The consideration of these strain rates within the frame-work of the Timoshenko theory led to the discovery of new mechanisms of de-formation of laminated beams which the classical theory does not find. It is shown that the change in mechanism of deformation can occur by increasing the density of reinforcement of shelves or walls.
\end{abstract}

Keywords: metal-composites, reinforcement, laminated beams, steady state creep, Timoshenko theory, Bernoulli theory, non-uniqueness of solution.

(C) 2016 Samara State Technical University.

Please cite this article in press as:

Yankovskii A. P. A study of steady creep of layered metal-composite beams of laminatedfibrous structures with account of their weakened resistance to the transverse shift, Vestn. Samar. Gos. Tekhn. Univ., Ser. Fiz.-Mat. Nauki [J. Samara State Tech. Univ., Ser. Phys. \& Math. Sci.], 2016, vol. 20, no. 1, pp. 85-108. doi: 10.14498/vsgtu1459. (In Russian)

Author Details:

Andrei P. Yankovskii (Dr. Phys. \& Math. Sci.; lab4nemir@rambler.ru), Leading Research Scientist, Lab. of Fast Processes Physics. 
Acknowledgments. This work has been supported by the Russian Foundation for Basic Research (project no. 14-01-00102-a).

\section{ORCID}

Andrey P. Yankovskii: http://orcid.org/0000-0002-2602-8357

\section{REFERENCES}

1. Karkauskas R., Krutinis A., Atkočiūnas J., Kalanta S., Nagevičius J. Stroitel'naia mekhanika. Programmy i resheniia zadach na EVM [ Structural Mechanics. Programs and Solution of Problems by PC]. Moscow, Stroiizdat, 1990, 360 pp. (In Russian)

2. Nemirovskii Yu. V., Mishchenko A. V., Vokhmianin I. T. Ratsional'noe i optimal'noe proektirovanie sloistykh sterzhnevykh sistem [Rational and optimal design of laminated beam systems]. Novosibirsk, 2004, 488 pp. (In Russian)

3. Kompozitsionnye materialy [Composite Materials], ed. V. V. Vasil'ev, Iu. M. Tarnopol'skii. Moscow, Mashinostroenie, 1990, 512 pp. (In Russian)

4. Kachanov L. M. Teoriia polzuchesti [Theory of Creep]. Moscow, Fizmatgiz, 1960, 456 pp. (In Russian)

5. Rabotnov Yu. N. Creep problems in structural members. Amsterdam, London, NorthHolland Publ. Co., 1969, xiv+822 pp.

6. Radchenko V. P., Eremin Yu. A. Reologicheskoe deformirovanie i razrushenie materialov $i$ elementov konstruktsii [ Rheological Deformation and Fracture of Materials and Structural Element]. Moscow, Mashinostroenie-1, 2004, 264 pp. (In Russian)

7. Mishchenko A. V., Nemirovskii Yu. V. Creep of the homogeneous and layered beams on the basis of a three-component model, Izv. vuzov. Stroitel'stvo, 2009, no. 5, pp. 16-24 (In Russian).

8. Feodos'ev V. I. Soprotivlenie materialov [Strength of materials]. Moscow, Nauka, 1986, 512 pp. (In Russian)

9. Yankovskii A. P. An analysis of the established creep of reinforced metalocomposite wallbeams in view of the weakened resistance to in-plane shear, Mekhanika kompozitsionnykh materialov $i$ konstruktsii [Journal on Composite Mechanics and Design], 2012, vol. 18, no. 3, pp. 301-319 (In Russian).

10. Yuzikov V. P., Panasenko N. N. Stroitel'naia mekhanika tonkostennykh sterzhnei [Construction mechanics of thin walled rods]. Volgograd, Volgograd Science Publ., 2013, 361 pp. (In Russian)

11. Vasil'ev V. V. Mekhanika konstruktsii iz kompozitsionnykh materialov [Mechanics of Composite Structures]. Moscow, Mashinostroenie, 1988, 272 pp. (In Russian)

12. Washizu K. Variational Methods in Elasticity and Plasticity. New York, Pergamon Press, 1982, xv+630 pp.

13. Yankovskii A. P. Modelling of mechanical behaviour is cross reinforced metal-composites in conditions of the steady creeping, Mekhanika kompozitsionnykh materialov $i$ konstruktsii [Journal on Composite Mechanics and Design], 2011, vol. 17, no. 3, pp. 362-384 (In Russian).

14. Pisarenko G. S., Mozharovskii N. S. Uravneniia $i$ kraevye zadachi teorii plastichnosti $i$ polzuchesti [Equations and Boundary Value Problems of the Theory of Plasticity and Creep]. Kiev, Naukova dumka, 1981, 496 pp. (In Russian)

15. Kompozitsionnye materialy [Composite Materials], ed. D. M. Karpinos. Kiev, Naukova dumka, 1985, 592 pp. (In Russian)

16. Nikitenko A. F. Polzuchest' i dlitel'naia prochnost' metallicheskikh materialov [Creep and Long-Term Strength of Metallic Materials]. Novosibirsk, 1997, 278 pp. (In Russian)

17. Perelmuter A. V., Slivker V. Stability of inelastic systems, Handbook of Mechanical Stability in Engineering, vol. 3, More Challenges in Stability Theories and Codification Problems, World Scientific Publ., 2013, pp. 1189-1271. doi: 10.1142/9789814383769_0017. 
18. Yankovskii A. P. Assessing ultimate loading levels of shells of revolution with complex reinforcement under creep, Problemy prochnosti i plastichnosti [Problems of Strength and Plasticity], 2010, no. 72, pp. 63-72 (In Russian).

Received 13/XI/2015;

received in revised form 11/II/2016;

accepted 26/II/2016. 